\title{
A RELAÇÃO ENTRE A ATIVIDADE DO BRINCAR E A ATIVIDADE DE ESTUDOS NA TRANSIÇÃO DA PRÉ-ESCOLA PARA O ENSINO FUNDAMENTAL
}

\author{
Fabiana Lohani de Sousa, José Ricardo Silva e Irineu Aliprando Tuim Viotto Filho. \\ Universidade Estadual Paulista - UNESP, Presidente Prudente, SP. E-mail: $\underline{\text { fabianalohani@hotmail.com. }}$
}

\section{RESUMO}

O desenvolvimento humano apresenta certa periodização derivada das relações estabelecidas com a realidade. Em cada período, as chamadas atividades principais guiam o desenvolvimento humano. Sob relações humanas de qualidade, há mudança de uma atividade principal para outra, indicando a viragem no desenvolvimento. Isso não quer dizer que a atividade anterior desaparece, mas ocupa papel secundário. Na idade pré-escolar, a atividade guia é a brincadeira, posteriormente a atividade guia será a atividade de estudo. Contudo, de modo geral, a escola desconsidera a brincadeira e prioriza apenas a atividade de estudo. Por esta razão, o objetivo deste artigo é defender a atividade do brincar como atividade secundaria e auxiliar na atividade de estudo. $O$ estudo bibliográfico nos permite defender a importância de uma passagem paulatina da brincadeira para a atividade de estudo enfatizando o papel do professor como mediador desse processo, de modo que aconteça sem rupturas abruptas, como tem ocorrido na escola.

Palavras-Chave: Atividade guia, brincadeira, estudo, desenvolvimento, escola.

\section{THE RELATIONSHIP BETWEEN PLAY ACTIVITY AND STUDY ACTIVITY IN THE TRANSITION FROM PRE-SCHOOL TO ELEMENTARY SCHOOL}

\begin{abstract}
Human development presents a certain periodization derived from relations established with reality. In each period, the so-called core activities guide human development. Under quality human relationships, there is a shift from one major activity to another, indicating a turning point in development. This is not to say that the previous activity disappears, but it plays a secondary role. At the preschool age, the activity guide is the play, later the activity guide will be the study activity. However, in general, the school ignores the joke and prioritizes only the activity of study. For this reason, the objective of this article is to defend the activity of playing as a secondary activity and to assist in the study activity. The bibliographic study allows us to defend the importance of a gradual passage from the game to the study activity emphasizing the role of the teacher as mediator of this process, so that it happens without abrupt ruptures, as it has happened in the school.
\end{abstract}

Keywords: Activity guide, play, study, development, school. 


\section{INTRODUÇÃO}

Nossos estudos e reflexões a partir da teoria histórico-cultural vêm afirmando a importância e a necessidade de relações sociais de qualidade humanizadora para o desenvolvimento psíquico das crianças. Segundo Leontiev (1978) o homem se humaniza a partir da educação, pois tudo o que Ihe torna ser humano é resultado de um processo de apropriação advindo de sua vida em sociedade, no seio da cultura historicamente formada pelo coletivo de indivíduos. Rego (1995) afirma que todo ser humano vive importantes interações desde o seu nascimento. Para a autora

Desde o nascimento, o bebê está em constante interação com os adultos, que não só asseguram sua sobrevivência, mas também medeiam a sua relação com o mundo. Os adultos procuram incorporar as crianças à sua cultura, atribuindo significado às condutas e aos objetos culturais que se formaram ao longo da história (REGO, 1995, p.59).

Compreendemos, portanto, que no processo de desenvolvimento, o ser humano se sobressai aos demais animais, pois além das suas características hereditárias e experiência individual, consegue apropriar-se e objetivar-se pela internalização de signos, linguagens e conceitos fundamentais para desenvolver pensamentos, sentimentos e sua consciência (LEONTIEV, 1978).

Neste sentido, destaca-se a escola como instituição fundamental no processo de humanização das crianças, principalmente quando cumpre sua função social na transmissão dos conhecimentos construídos e sistematizados pela humanidade, como afirma Saviani (2000) e, evidentemente, ao professor cabe a tarefa de criar condições em sala de aula para a efetivação desse processo.

Para Saviani (2000) o trabalho educativo é o ato de produzir direta e intencionalmente em cada indivíduo singular, a humanidade construída histórica e coletivamente pelo conjunto dos homens, ou seja, no processo de desenvolvimento da criança, há que se educar, assim como possibilitar o acesso a diferentes objetos culturais pois é desta forma que toda criança tem a oportunidade de se educar e se humanizar.

Para um alto nível de desenvolvimento humano é preciso que o professor possibilite aos sujeitos da educação não somente qualquer conhecimento, mais sim o que há de mais elaborado pela humanidade, o que para Saviani (2000) constitui-se no conhecimento "clássico", ou seja, todas as obras científicas, filosóficas, artísticas e outras que, pela sua qualidade, se perpetuaram ao longo da história.

Acreditamos que o atual processo de escolarização, sobretudo, com a entrada precoce da criança no Ensino Fundamental, sem as devidas preocupações no que tange sua especificidade e a importância do brincar nesse período do desenvolvimento, pode estar contribuindo para uma fragmentação do sentido e significado da atividade de estudar, fato que pode dificultar o processo de aprendizagem e desenvolvimento da criança nesse nível de ensino.

Temos visto que esse processo de passagem da pré-escola para o ensino fundamental não tem sido adequadamente cuidado pela escola, pois as crianças necessitam de apoio e suporte psico-pedagógico para enfrentar essa nova etapa de sua vida escolar, tendo em vista que a natureza da escola de educação infantil, cuja atividade principal é o brincar, diferencia-se da natureza da escola de ensino fundamental, cuja atividade principal é o ato de estudar, passagem essa que precisa ser devidamente investigada e compreendida.

Diante dessa introdução, objetivamos defender a atividade do brincar como atividade secundaria e auxiliar na atividade de estudo, as quais precisam se relacionar para o bom desenvolvimento da criança que chega no Ensino Fundamental. 


\section{METODOLOGIA}

A metodologia utilizada neste trabalho é de caráter bibliográfica. De acordo com Gil (2008), a pesquisa bibliográfica é aquela que utiliza material já elaborado, uma base de dados constituída por livros e artigos científicos sobre o tema abordado.

\section{RESULTADOS}

Para esta função docente a qual nos orienta Saviani (2000) é importante levar em consideração que, o desenvolvimento humano apresenta certa periodização. Facci (2004) apoiada nos autores da referida teoria, explica que em cada período, algumas atividades se tornam mais importantes que as outras, as chamadas atividades principais. Cabe dizer que a atividade principal é aquela que "[...] governa as mudanças mais importantes nos processos psíquicos e nos traços psicológicos da personalidade da criança, em um certo estágio de seu desenvolvimento" (LEONTIEV, 1978, p. 65). Logo, o desenvolvimento psíquico depende da atividade principal e não da ação em geral. Valendo-nos dos estudos de Leontiev (1978), Mukhina (1996) e Elkonin (2009), destacamos que as atividades principais são: relação emocional com adultos, manipulação objetal, brincadeira de papeis sociais, atividade de estudo, relação íntimo pessoal e o trabalho.

Marcada por crises, rupturas e saltos qualitativos, tal periodicidade é derivada das relações estabelecidas com a realidade, já que, histórica e dialeticamente, são estas relações que operam o desenvolvimento humano. Portanto, esta periodização do desenvolvimento, no entanto, não está alheia às condições concretas de vida do indivíduo. Ela está permeada de influências históricas e sociais do meio em que vive. Isto significa que não é a idade cronológica que irá predizer o período em que a criança se encontra, mas a maturação biológica e as condições históricas e sociais nas quais o desenvolvimento da criança ocorre.

A mudança no estágio psíquico é, necessariamente, a mudança de atividade principal na relação entre a criança e a sua realidade. Essas mudanças também indicam qual a atividade corresponde a mais importante para o estágio no qual a criança se encontra. Do mesmo modo que as vivências possibilitam tal desenvolvimento, as qualidades das relações estabelecidas pelo indivíduo mudam. A criança, no caso, perde o interesse naquilo que ocupava maior parte de seu tempo. Surge o novo, novas formações na estrutura da personalidade e da atividade, configurando-se em mudanças psíquicas e sociais que se produzem a partir das estruturas já fixadas. A própria criança começa a perceber que as ações de rotina não correspondem mais às suas potencialidades e, a partir daí, como cita Leontiev (1989, p. 66), busca potencializá-las.

Surge uma contradição explícita entre o modo de vida da criança e suas potencialidades, as quais já superaram este modo de vida. De acordo com isso, sua atividade é reorganizada e ela passa, assim, a um novo estágio no desenvolvimento de sua vida psíquica.

Dialeticamente, estas novas formações tendem a ocupar um plano de fundo quando, em desenvolvimento, outras novas formações emergem. São justamente estas novas formações, estas mudanças na personalidade, o critério fundamental para compreender o desenvolvimento infantil. Nesta perspectiva, o desenvolvimento está em movimento revolucionário (VIGOTSKI, 1987).

Estes esclarecimentos revelam que em determinados momentos, as linhas centrais irão se converter em linhas acessórias e vice-versa. Para o autor, os momentos de viragem entre uma atividade para outra são, relativamente, os mais difíceis de educar as crianças. Este seu posicionamento, relaciona-se à crítica ao sistema educacional que não atinge tais mudanças na personalidade, não contribuindo com o objetivo institucional de contribuir com o desenvolvimento.

É neste desenvolvimento que reconhecemos que, em determinado momento da vida das crianças, há interesse pela atividade do brincar, atividade guia da infância e, esta atividade não 
pode ser desqualificada apenas pelo fato da criança frequentar a escola de ensino fundamental. É preciso que os professores conheçam e reconheçam nas crianças a atividade interna de brincar ou de estudos de modo a entender que uma atividade é auxiliar a outra, ou seja, maiores saltos qualitativos no desenvolvimento poderão ser dados quando a criança estuda pesquisa e descobre de forma lúdica.

\section{DISCUSSÃO}

As experiências e conhecimentos construídos pela humanidade são garantidos a criança através do ensino e da aprendizagem na escola, sendo que o professor é o mediador desse processo. O professor, além de constituir-se como um sujeito mais desenvolvido que a criança, tem como função, o importante papel na transmissão do conhecimento, assim como na socialização de objetos materiais e simbólicos, fato que se dá através dos processos de ensino na escola, pois a adaptação e desenvolvimento das crianças dependem de seu trabalho educativo, sobretudo nos momentos de transição como acontece na passagem da pré-escola para o Ensino Fundamental.

A escola é espaço de desenvolvimento humano, sobretudo quando falamos da passagem de um nível de ensino para outro de natureza superior, de forma a valorizarmos ambos como fundamentais na vida das crianças. Defendemos, sobretudo na passagem da pré-escola para o Ensino Fundamental o papel mediador do professor no estabelecimento da relação entre a atividade do brincar e a atividade de estudo que será a principal nesse nível de ensino.

Acreditamos que as crianças em processo de transição da atividade do brincar para a atividade de estudo, precisam viver essa condição paulatinamente, para que não se sintam prejudicados devido a súbita mudança que decorre da passagem da educação infantil para o Ensino Fundamental. Esse fato pode dificultar o seu processo de desenvolvimento como salientamos acima, justamente porque, conforme apregoa a teoria histórico-cultural, a criança relaciona-se com o mundo e supre suas necessidades a partir do brincar, fato importante a ser considerado no 10. ano do Ensino Fundamental.

Reconhecemos que todo ser humano precisa do contato social, desde seu nascimento e da apropriação de bens culturais, para se constituir como ser humano e, para a criança, a forma principal de se relacionar com o mundo adulto e se apropriar da cultura é a brincadeira. Esta compreensão nos ajuda a refutar concepções que priorizam a atividade de estudo como única forma para o desenvolvimento na infância. Ao contrário, para além de uma formação teórica e de socialização dos conhecimentos clássicos, o professor precisa se preocupar em formar seus estudantes a partir da prática social e, nesse sentido, a prática social da criança de 06 anos configura-se principalmente pela brincadeira, fato importante a ser considerado pelo professor do 10. ano do Ensino Fundamental, para que a criança, paulatinamente, possa chegar na atividade de estudo sem maiores dificuldades. Destacamos que ao pensar na atividade através da teoria Histórico-Cultural, Rego (1995) aponta que:

Para Vygotsky, o ensino sistemático não é o único fator responsável por alargar os horizontes da zona de desenvolvimento proximal. Ele considera o brinquedo uma importante fonte de promoção ao desenvolvimento. Afirma que apesar do brinquedo não ser o aspecto predominante da infância, ele exerce uma enorme influência no desenvolvimento infantil (REGO, 1995 p.81).

Para nós, a atividade do brincar pode chegar nas séries iniciais do ensino fundamental como atividade secundaria, ou seja, não há razão para impedir as crianças de brincar nas séries iniciais, desde que essa atividade complemente as atividades principais de estudo. 


\section{CONSIDERAÇÕES FINAIS}

O texto parte da problemática relação entre a infância e os estudos no primeiro ano do Ensino Fundamental. Temos visto que, a transição entre a pré-escola e o Ensino Fundamental desconsidera a brincadeira como linguagem específica da criança. Nesta relação, o desenvolvimento encontra-se limitado. Assim, o objetivo foi discutir a relação entre a atividade do brincar e a atividade de estudos junto a crianças em fase de transição da pré-escola para o Ensino Fundamental.

De acordo com os autores explorados, o desenvolvimento, marcado por saltos qualitativos, é guiado pelas denominadas atividades principais. Na mudança de uma atividade principal para a outra, a anterior toma função de pano de fundo daquela que se torna principal, ou seja, não desaparece, exerce um papel secundário. Isso significa que, de modo geral, quando as crianças chegam no Ensino Fundamental, a atividade guia do desenvolvimento é a atividade de estudo e a brincadeira é a atividade secundária.

Estamos considerando a importância de uma passagem paulatina da brincadeira para a atividade de estudo e enfatizando o papel do professor como mediador desse processo, sobretudo porque identificamos um grande número de crianças que vivem dificuldades de aprendizagem nas séries iniciais do Ensino Fundamental que pode ser decorrente dessa mudança abrupta de atividade social. Defendemos, portanto, que esse processo aconteça sem rupturas abruptas, como tem ocorrido na escola.

\section{REFERÊNCIAS}

ELKONIN D. B. Psicologia do jogo. São Paulo, Martins Fontes, 2009.

FACCI M. G. D. A periodização do desenvolvimento psicológico individual na perspectiva de Leontiev, Elkonin e Vigotski. Cadernos Cedes, Campinas, vol. 24, n. 62, p. 64-81, abril 2004. Disponível em: http://www.scielo.br/pdf/ccedes/v24n62/20092.pdf Acesso em: 12 de jan de 2016.

GIL, A. C. Como elaborar projetos de pesquisa. 4. ed. São Paulo: Atlas, 2008.

LEONTIEV, A. O desenvolvimento do psiquismo. Lisboa: Horizonte, 1978.

MUKHINA V. Psicologia da idade pré-escolar. São Paulo, Martins Fontes, 1996.

REGO, T. C. Vigotsky: Uma perspectiva histórico-cultural da educação. Petrópolis, RJ: Vozes, 1995 (educação e conhecimento).

SAVIANI, D. Pedagogia histórico-crítica: primeiras aproximações. Campinas: Autores Associados, 2000.

LEONTIEV, A. Uma contribuição à teoria do desenvolvimento da psique infantil. In: Linguagem, desenvolvimento e aprendizagem. VIGOTSKII L.S., LURIA A.R. e LEONTIEV A.N., 2a ed., Ícone editora, São Paulo, 1989.

VYGOTSKI, L. S. Pensamento e linguagem. Trad. Jefferson L. Camargo. São Paulo: Martins Fontes, 1987. 